Research Article

\title{
Optimizing the Construction of Multidimensional System of Entrepreneurship Education from the Perspective of the Second Classroom
}

\author{
Meng-Xi Zhu $\mathbb{D}^{1},{ }^{1}$ In-Jae Kim $\mathbb{C}^{,},{ }^{2}$ and Zhi-Quan An $\mathbb{C}^{3}$ \\ ${ }^{1}$ Student Affairs Office, Beihua University, Jilin City, China \\ ${ }^{2}$ Hoseo University, Asan, Republic of Korea \\ ${ }^{3}$ School of Economics and Management, Beihua University, Jilin City, China \\ Correspondence should be addressed to Zhi-Quan An; bh1702@126.com
}

Received 7 September 2021; Accepted 18 November 2021; Published 28 December 2021

Academic Editor: Punit Gupta

Copyright $(2021$ Meng-Xi Zhu et al. This is an open access article distributed under the Creative Commons Attribution License, which permits unrestricted use, distribution, and reproduction in any medium, provided the original work is properly cited.

Construction of the entrepreneurial ability evaluation system based on the Communist Youth League's second class is presented in this paper. Drawing on the advanced experience of foreign countries and in accordance with the requirements of UNESCO, the objectives of innovation and entrepreneurship education should be integrated into school education and teaching objectives, and the content, curriculum, and atmosphere of social entrepreneurship education should be highlighted, with the effectiveness of entrepreneurship education as the focus of practice. Combining the characteristics and advantages of all disciplines and disciplines, we will create an innovative and pioneering education system that integrates interyear, interdisciplinary, interdisciplinary, and distinctive features and infiltrates the entire process of cultivating outstanding professionals in various fields. Through entrepreneurship education, general education courses to guide students to focus more on professional courses pay more attention to the latest developments in professional fields and innovation thus optimizing their knowledge structure and cultivating their innovative thinking, entrepreneurial awareness, and professional competence

\section{Introduction}

With the continuous promotion of the education authorities and universities, college students' entrepreneurship and entrepreneurship education have quickly become a hot spot in higher education. However, there are still many areas worthy of improvement and optimization in the environment for entrepreneurship and entrepreneurship education that mainly manifested in [1-3]: the tripartite linkage mechanism between local governments, universities, and individual students under the framework of entrepreneurship education has not yet been established, and policies supporting college students' entrepreneurship have not yet been implemented (Figure 1).

The core of the entrepreneurship is innovation. Entrepreneurship based on innovation is full of vitality and has only sustainable development. China's urban economic structure shows transition from a big manufacturing country to a strong manufacturing country. Therefore, the basic elements of an innovative city include management innovation, technological innovation, and the industrial innovation. The curriculum system is a comprehensive reflection of the goal of the personnel training and teaching philosophy. The curriculum system to a certain extent determines the students' knowledge structure and ability structure [4].

The research on the establishment of entrepreneurial education curriculum is not only the need of improving the theory of the entrepreneurship education but also the actual need of then carrying out the undertaking education activities. To combine the curriculum system of entrepreneurship education with successful entrepreneurs, we must have entrepreneurial consciousness, personality traits, core competence, and social knowledge structure. 


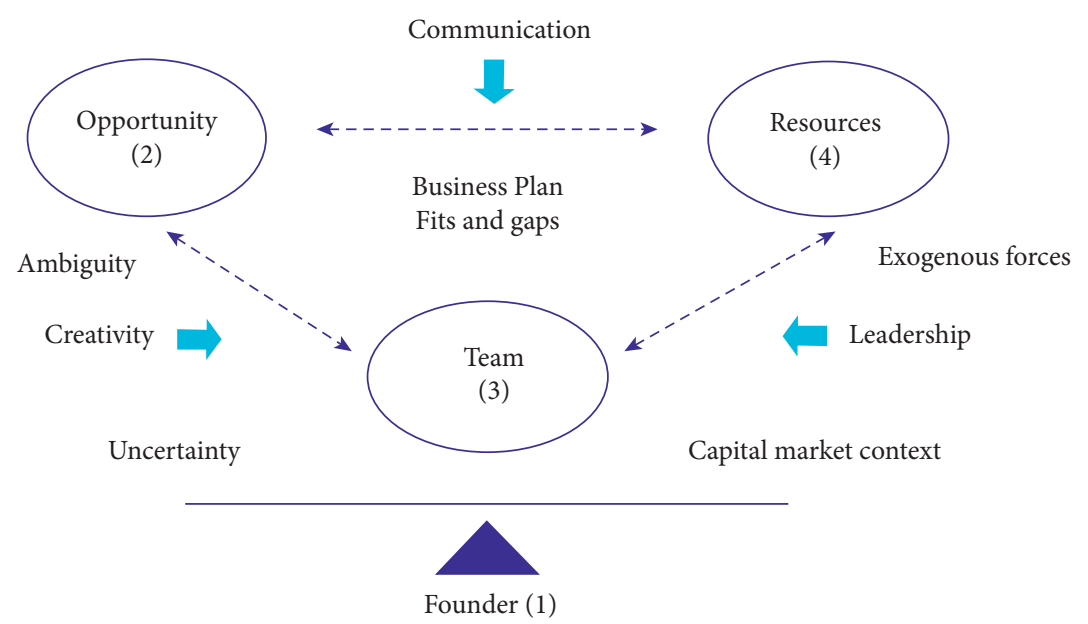

FIgURE 1: The entrepreneurial ability evaluation system framework.

The construction of the high-tech venture risk evaluation index system should also follow the following principles $[5,6]$. (1) Scientific principle: the scientific principle is the basis of constructing the index system of high-tech venture risk. Its main performance indicators in the selection and design should have a theoretical basis, to grasp the regularity and creativity. (2) The principle of the development: enterprises of the same nature are faced with different risks in different periods, especially in the current market economy of our country. Because of the economic system, industrial policy, exchange rate policy, capital market, and other factors that have a significant impact on entrepreneurship are still not stable. High-tech entrepreneurship is facing a lot of uncertainty. (3) Systematic, targeted, and some operational principles: the various risks enterprises face in starting a business do not exist in isolation. They are interrelated and influence each other. In the construction of the index system, we should consider these risk factors as an organic system, analyze the risks that high-tech start-ups face, and at the same time pay attention to the measurability and accessibility of the indicators.

With the goal of cultivating outstanding professionals in various fields, a comprehensive and systematic course system of the innovation and entrepreneurship education and a first and second classroom interaction are set up. The comprehensive platform for interyear, interdisciplinary, and interdisciplinary entrepreneurship practice combines organic integration of general simulated exercises and actual exercises focusing on building a distinctive "one core, three platforms, and nine modules" innovation, and the entrepreneurship education system guides and helps college students change the employment concepts, broaden the entrepreneurial channels, cultivate innovative ability to create entrepreneurial talent, and through continuous exploration, gradually built into distinctive features, significant results, and demonstrative ability to drive the national or provincial college students innovation and entrepreneurship education demonstration base. In Table 1, we show the principles that should be considered [7].

\section{Communist Youth League's Second Class}

The second class transcript of the core Communist Youth League refers to the mechanism of the first class and combines the characteristics of the second class with the transcripts of students' participation in the second class activities in a manner similar to that of traditional university transcripts. The emergence of transcripts in the second class has led to the explicit display. As a forward front of ideological work, colleges and universities shoulder the important speech of the propaganda and general secretary series and new ideological and tactic strategies of governing state affairs and politics, nurturing and promoting the socialist core values and providing human resources protection for the realization of the Chinese dream of the great rejuvenation of the Chinese nation and intellectual support for the important task. Strengthening the ideological and political work in colleges and universities is a strategic project, a solid project, and a project of casting soul and is of great and farreaching significance.

The "Transcripts of Second Class" of colleges and universities cover most of the tasks and responsibilities of CYL in colleges and universities. They guide, record objectively, scientifically evaluate, and promote the growth of students and systematically modularize and dataize students' participation in the second classroom. Students will be provided with a demonstration of self-evidence of some scientific evaluation systems as effectively leading students to take the initiative to integrate into the ideological and political education. In the analysis and research of some related cases, the author believes that the establishment of the second classroom transcript system can be developed from the "three-step" strategy:

(i) System and scientific assessment is the important link of the second class report card system. In order to then establish the system of the system, we can learn the pattern mechanism of the first class and combine the characteristics of the second classroom activity, such as attendance, ordinary performance, and final grade. 
TABLE 1: The principles for the construction of the entrepreneurial ability evaluation system.

\begin{tabular}{lc}
\hline Principles & Details \\
\hline $\begin{array}{l}\text { Introduce the system of instructor and enhance the effectiveness of } \\
\text { the system }\end{array}$ & $\begin{array}{c}\text { Gradually establish a university venture research institutions. The } \\
\text { sustainable development of college students' entrepreneurship } \\
\text { education cannot be separated from the support of research work. } \\
\text { Colleges and universities are the main front of scientific research } \\
\text { activities. University teachers generally have some research ability. } \\
\text { In setting up the education curriculum system, we pay attention to } \\
\text { the innovation and practicability of education, set up the education } \\
\text { public course, and gradually build up a relatively perfect system of } \\
\text { education courses with its own characteristics. }\end{array}$ \\
$\begin{array}{l}\text { Open entrepreneurship education public class and strengthen } \\
\text { students entrepreneurship awareness education }\end{array}$ & $\begin{array}{c}\text { Curriculum teaching can accumulate and deepen students } \\
\text { Professional knowledge embedded in innovation and } \\
\text { entrepreneurship and education to play an active role in professional } \\
\text { advantages and special talents }\end{array}$ \\
$\begin{array}{l}\text { entrepreneurship, and promote innovation and entrepreneurship } \\
\text { education in the whole process and individuation. }\end{array}$
\end{tabular}

(ii) The establishment of the second class transcript system should pay attention to analysis, reflecting the needs of multiple analysis, and from the student's point of view, the second classroom transcript will be that students of the second classroom education were dominant Through the analysis of the results, on the one hand, students gain a sense of achievement; on the other hand, it also stimulates students to selectively participate in the weak links in the second class to think. From the perspective of schools, big data analysis is used to provide scientific data for school second class education reform on the one hand, and effective data for student personality development analysis on the other hand.

(iii) On the basis of their own reality and characteristics, colleges and universities can further clarify and conclude the second classroom activities types and establish a scientific second classroom curriculum system based on the practice of quality development practice.

The fundamental purpose of the personalized education is to enable students to develop their good personality, character, and specialty by providing personalized development goals, paths, models, and evaluations for different types of students. So that students' personal potential can be fully developed. Personalized education thought originated in the 1960s humanistic philosophy of education. As early as the 1980s, Europe and the United States started the pilot reform of the personalized education. Harvard professor Howard Gardner also wrote in 2009 that the era of personalized education is coming.

Personalized education has become an international trend of education. Individualized education is an inevitable requirement to adapt to the diversified talent structure in modern society. It is an inevitable choice to realize the smooth transition of the higher education. It reflects the true meaning of the education and the return of education essence. It is an important measure for CYL to acquire youth identity through its own advantages. Therefore, we should consider the following regulations: (i) School material culture is the material carrier and guarantee of school spiritual culture. It is imperative to build a training base for students to cultivate their comprehensive qualities and at the same time strengthens the management of the characteristics of the community to then cultivate student sentiment, cultivate students' expertise, and enhance the employment competitiveness of students to lay the foundation.

(ii) Through the party branch's mass line education practice, service awareness and education awareness are raised. Through the mass line summary of education practice, improvement to participate in the students' cognitive ability, and actively guiding students to establish correct world outlook, the outlook on life, values, working for party, and government leadership attaches great importance to the basic campus culture construction attention responsible for the teacher correct guidance to participate in a strong situation of students' positive enthusiasm.

(iii) The work group of the Communist Youth League in Colleges and universities has a wide coverage and a good mass base. The campus culture activities carried out by the Communist Youth League activities are more vivid, and the leader role of student leaders is more effective.

Years of practical experience have proved that effective and high-quality social practice plays an important role in cultivating the comprehensive qualities of young people in relation to theory, innovative thinking, and social adaptability. In this sense, the second CYL education for the young people is an important guarantee for the all-round development of young people. Due to the change of the specific living environment and the continuous emergence of undesirable social phenomena in the transition period, the CYL must expand its relevant functions as needed to continuously innovate and improve the content and then form of the second class so as to provide assistance for the allround development of young people as shown in Table 2. 


\section{The Construction of Entrepreneurial Ability Evaluation System}

3.1. The Entrepreneurial Ability. Although there is a rapid development of our college students' innovation and basic entrepreneurship education, there are still some shortcomings and first teachers need to be strengthened urgently. Innovation and entrepreneurship education is a comprehensive quality education, not only to carry out innovation and entrepreneurship theoretical knowledge but also to pay attention to the stimulation of innovation and innovation and practical ability to improve. This requires that teachers not only have a wealth of the knowledge of innovative entrepreneurship but also have rich practical experience in innovation and entrepreneurship [8].

Broad sense of entrepreneurship refers to the postentrepreneurial, and narrow sense of the general business only refers to the own business. Around the basic meaning of the innovation and entrepreneurship, colleges and universities should take the following countermeasures in cultivating students' ability of innovation and entrepreneurship $[9,10]$. (1) Universities can organize a series of the innovation and entrepreneurship competition activities, cultivate students' innovative awareness, and improve students' innovation and entrepreneurship ability. Students are encouraged to actively participate in provincial, national innovation, and entrepreneurship competitions and academic activities. (2) The consciousness of innovation itself is a motive force and an accelerator of innovation. It dominates the creative ability of people and then promotes the cultivation and improvement of innovation ability. Cultivating students' consciousness of innovation and entrepreneurship is the basic goal of carrying out innovative and the entrepreneurial education in colleges and universities. The school publicises the innovation and entrepreneurship policies and successful entrepreneurs' experiences through the school magazine, the school radio station, the campus network, billboards, and other media to stimulate students' entrepreneurial enthusiasm. (3) Elective courses for innovation and entrepreneurship can include company law, modern enterprise system, innovative thinking, enterprise management, and entrepreneurship theory and practice. Students can choose appropriate courses and innovation and entrepreneurship practice activities according to their own interests and hobbies, so as to lay a good theoretical foundation for their own innovation and entrepreneurship. In Figure 2, we show the entrepreneurial ability and economic resources.

In terms of professional curriculum, there should combination with the characteristics of each professional and its key in basic conjunction with market, targeted to open innovation business-related courses and at the same time pay attention to the students' individual character development needs, according to their aptitude.

Colleges and universities should actively seek cooperation resources and establish multiple university-enterprise cooperation to create business incubators and gradually strengthen the university students innovative entrepreneurial atmosphere, kinds of innovation through entrepreneurship competition project to promote the practice of college students, through competition incentives to encourage the innovation of the college students entrepreneurship practice, provide students with more opportunities for innovation entrepreneurship practice, and promote the college students' innovative entrepreneurial ability of general ascension. The competitive situation in China's transition environment forces entrepreneurs to strengthen their learning to improve their own entrepreneurial ability, so as to improve the performance of new enterprises [11].

Although many scholars have emphasized the importance of the entrepreneurial learning to new company, existing research stays in the conceptual phase, and more entrepreneurial learning mechanism for new enterprises lack the corresponding empirical test. Teachers teach students ways to deal with the problems in the process of teaching, fully mobilize students involved in the actual teaching to let the students to use their own subjective initiative to solve the problem, and let the students in the learning process to realize their own sense of the accomplishment. After the students have achieved success, they have cultivated the correct learning method and cultivated a good attitude of learning $[12,13]$.

Students get a personal experience in learning and learn to create in the experience. Teachers use multimedia teaching instead of the traditional blackboard teaching, put forward corresponding problems, improve the classroom teaching atmosphere, improve students' practical ability, and guide the student to find problems in the learning process to solve. Students become masters of the learning in the process of solving problems, and teachers have some guidance around them, and the suggestions are listed as follows:

(i) Organization and management ability is the guarantee of business success and business development capacity relationship with the development of enterprise. On college students' entrepreneurs, business development capacity refers to have a keen sense of touch and the insight ability and able to capture the development trend of the industry. At the same time, it must have a strong ability to adapt and develop ability.

(ii) The improvement of college students' entrepreneurial ability requires the work of education, while the development of the education is more necessary for modern teaching methods, as well as the help of hardware facilities such as libraries, websites, and databases especially need to combine entrepreneurship education in colleges and universities practicality and other characteristics to establish a professional and advanced innovative entrepreneurial training department to let the students to fully experience the entrepreneurial practice under various scenarios.

(iii) Of course, our long-term exploration of the entrepreneurship education in the colleges and 
TABLE 2: The communist youth league's second class suggestions.

\begin{tabular}{lr}
\hline Suggestions & \multicolumn{1}{c}{ Details } \\
\hline $\begin{array}{l}\text { Stimulate wisdom and mobilize the enthusiasm } \\
\text { of students }\end{array}$ & $\begin{array}{l}\text { Each student has advantages such as fully exploiting its inherent potential and guiding } \\
\text { them to participate actively in the second class of the Communist Youth League. This } \\
\text { requires that the CYL must formulate a set of incentive policies that motivate students } \\
\text { and teachers to participate and establish a way to encourage as many students as possible } \\
\text { to participate in the second classroom activities and to maximize student motivation, } \\
\text { initiative, and creativity. }\end{array}$ \\
$\begin{array}{l}\text { To truly implement, we must establish the three-level management system from the } \\
\text { school Youth League Committee, the Youth League Committee, and the class league } \\
\text { branch. In this process, the guiding role of the teachers is very important. Under the } \\
\text { guidance of professional teachers, the students' confusion period is shortened, and the } \\
\text { enthusiasm of participating in the second class is also then improved. } \\
\text { It will improve teaching effectively and promote students development and }\end{array}$ \\
$\begin{array}{l}\text { All-round evaluation to promote the all-round } \\
\text { development of students }\end{array}$ & $\begin{array}{r}\text { improvement to establish an evaluation system with multiple evaluation subjects and } \\
\text { comprehensive evaluation contents and diversified evaluation methods. }\end{array}$ \\
\hline
\end{tabular}

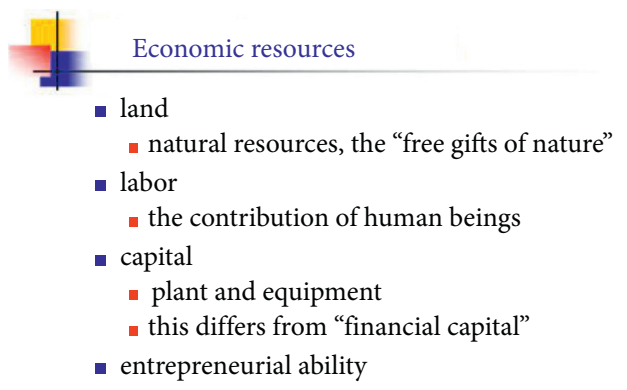

Figure 2: The entrepreneurial ability and economic resources.

universities has made some progress, but because the entrepreneurship education is still in the initial stage, the idea of education act too utilitarian and simple and entrepreneurship education has been in the job training and training work. In the current stage, self-employment education needs to be developed, so as to achieve the integration of the three aspects such as self-employment education, quality education, and regular education and deepen the educational reform.

3.2. The Business Evaluation Model. Through the research on evaluation and safeguard measures of entrepreneurship ability both at home and abroad, we can find that because college students start a business as a dynamic process, they need complex dynamic research and sequence analysis in methodology [14]. Many research studies tend to analyze the composition of entrepreneurial ability of the college students through questionnaire analysis to obtain the corresponding data as shown in Figure 3.

After the establishment of the index system and evaluation criteria of the internal performance evaluation control system of an enterprise, the final evaluation result needs to be quantified through the evaluation score method. The evaluation scoring method generally adopts a certain measurement model to unify the evaluation indexes of different types and types of systems and finally obtains the clear and definite evaluation results and then forms the evaluation conclusion and further completes the evaluation report. Because the interpersonal comprehensive ability is a comprehensive study of the interpersonal communication ability of the college students, in the face of complex entrepreneurial process, identification is conducive to college students to grasp the corresponding entrepreneurial opportunities and develop good executive ability as entrepreneurial project exercises, for college students venture to maintain good interest in order to effectively motivate students to start their own businesses, so the overall regression of these variables is more significant but also in line with the college students entrepreneurship theory and public awareness. In addition, full absorption of social human resources to make up for teachers hired successful entrepreneurs as visiting professors in entrepreneurship education, to carry out short-term teaching. Open lectures participate in case discussions to give students a professional guidance and evaluation of business plans but also pay attention to the professional growth of entrepreneurship teachers, to create more opportunities for teachers to enhance training. Through holding entrepreneurial teaching seminars, organizing teachers to attend the entrepreneurial academic conferences, and so on, special training for teachers is carried out to improve the quality of practitioners.

3.3. The Entrepreneurship System. Although we have given different explanations and choices about the concepts and curricula of the general education, the related theoretical research and practical exploration are also different [15]. However, the core concept always focuses on the all-round development of the "people" themselves. Therefore, we believe that general education is part of the nonprofessional education in college education. It is a "common education" that prepares students for any major study, aiming to cultivate social citizens with social responsibility, that sound personality, broad vision, and all-round development. The goal of the entrepreneurship education at three levels of the target orientation is as follows: first, on the whole, the basic goal of entrepreneurship education is to cultivate college students entrepreneurial awareness and entrepreneurial ability, to promote the practice of planning students; second, from colleges and universities, the goal of entrepreneurship 


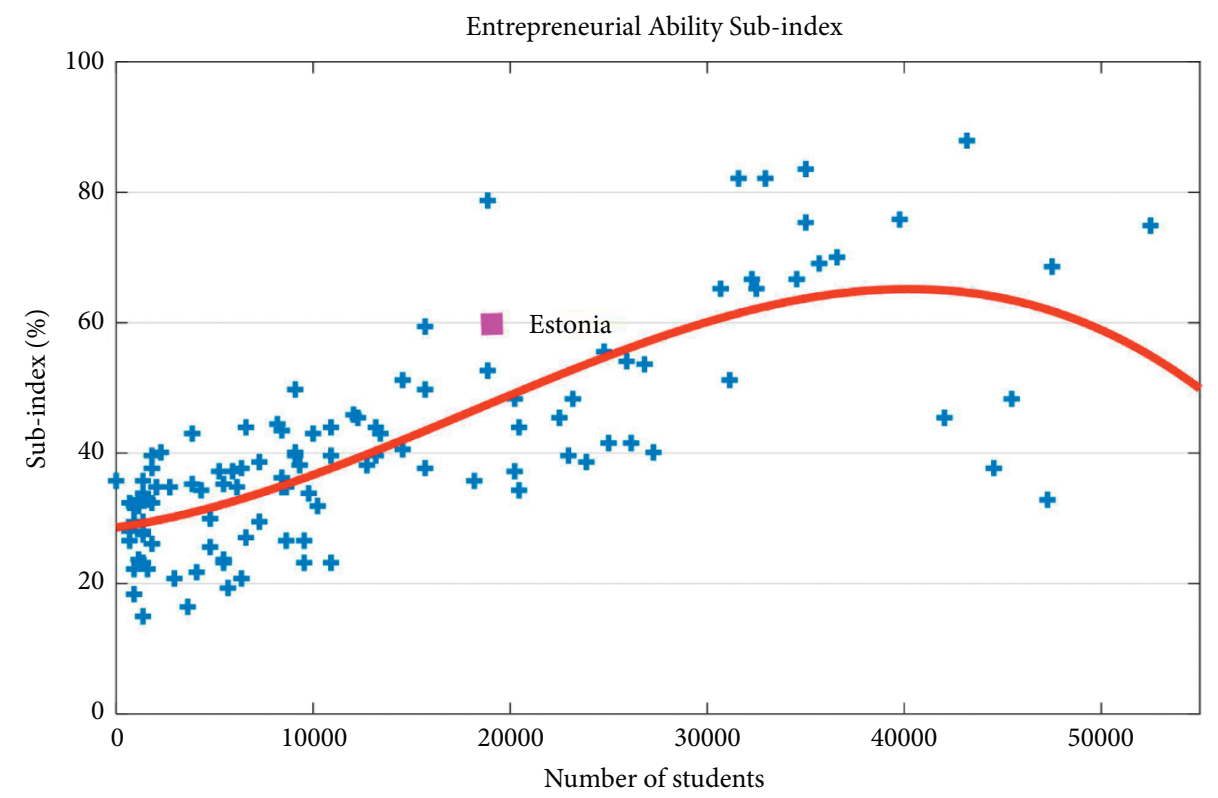

FIgURE 3: The business evaluation model simulation.

education is to cultivate the basic ability and pioneering personality of college students in different fields so that they have a good sense of entrepreneurship, entrepreneurial psychology, and entrepreneurial ability and form awareness and habits of initiative and research study; thirdly, from the perspective of individual students, the purpose of accepting startup education should be to cultivate their own professionalism and sense of responsibility, pioneering personality, the spirit of adventurousness, ability to work independently, and entrepreneurial ability to adapt to the changing social and professional environment, as well as the ability to coexist and collaborate with others.

After several years of practice, it is not hard to find that this model of entrepreneurship education did not rise to the level of concept guidance. There are some unavoidable problems, and without a clear distinction between the subject knowledge and the meaning of "creative" goals and the understanding of entrepreneurial talent, the sense of entrepreneurial entrepreneurship as well as the overall quality of entrepreneurship has not been truly cultivated. The knowledge structure needed by the students cannot be completely constructed. In the summary, we finalize the following suggestions. (1) In order to overcome the limitations of the traditional theory of classroom teaching to cultivate the real sense of entrepreneurial talent, entrepreneurship research needs to be actively carried out. Special entrepreneurship research institutions should be set up to carry out entrepreneurship education and entrepreneurship capacity building research. (2) Utilize favorable social resources, invite outside entrepreneurs, entrepreneurship successful people, and hold some business forums and lectures on a regular basis to tell students about the business process and share their entrepreneurial experience. Colleges and some universities should regularly carry out entrepreneurship competition plans to provide students with practice simulation opportunities. In addition, all-round guidance and support for the entrepreneurship students in schools should be given full play to the typical radiation role and a strong entrepreneurial atmosphere to promote the development of entrepreneurship education in higher education institutions. (3) College student startup education is the education that all college students should accept. It has the properties of the education. According to the basic idea of the general education in building the university entrepreneurship education curriculum system, popularize entrepreneurship education in ordinary colleges and universities as soon as possible, and the curriculum is the effective way to improve the quality of the entrepreneurship education in colleges and universities.

\section{Conclusion}

Construction of the entrepreneurial ability evaluation system based on the Communist Youth League's second class is presented in this paper. The basic knowledge of entrepreneurship theory is the main focus of the school to promote innovation and entrepreneurship. According to the students' essential knowledge, ability, and quality structure, they build up three modules and a three-dimensional foundation platform for entrepreneurship teaching. The cultivation of entrepreneurial talent's comprehensive qualities requires that the students' social adaptability and innovative ability be highlighted, and the limitation of professional adaptation in the past should be exceeded by one-sided emphasis on personnel training in higher education in which emphasis should be put on equally on both theory and practice, persistence in theory, and practice in personnel training. 


\section{Data Availability}

The datasets used and/or analyzed during the current study are available from the corresponding author on reasonable request.

\section{Conflicts of Interest}

The authors declare that there are no conflicts of interest with respect to the research, authorship, and/or publication of this article.

\section{Acknowledgments}

This paper is a teaching and research project of Beihua University: Research on the construction of multidimensional teaching system of entrepreneurship education in colleges and universities (Grant xjyb20210001).

\section{References}

[1] M. Shahbani, A. Bakar, and A. Azmi, "Improving entrepreneurial opportunity recognition through web content analytics," Journal of Telecommunication, Electronic and Computer Engineering, vol. 9, no. 2-11, pp. 71-76, 2017.

[2] T. Nikraftar, E. Hosseini, E. Hosseini, and E. Hosseini, "Factors affecting entrepreneurial opportunities recognition in tourism small and medium sized enterprises," Tourism Review, vol. 71, no. 1, pp. 6-17, 2016.

[3] E. A. Wood, "Towards a perceptual model of corporate entrepreneurial activity: a focus on the South African financial sector (Doctoral dissertation)," 2016, https://www. semanticscholar.org/paper/Towards-a-perceptual-model-ofcorporate-activity\%3A-a-Wood/e97d62ee4979894e5d2fe7a3 0e138ede1e581ece.

[4] N. Rahmawati, S. Hartono, L. Rahayu, and Masyhuri, "Innovative and creativity as entrepreneurial ability of organic rice farmers in Bantul, DIY," in Proceedings of the AIP Conference Proceedings, vol. 1755, no. 1, p. 130002, September 2016.

[5] F. Hongyan, R. G. LianXiaojie, and L. Wei, "Explaining the relationship between entrepreneurial learning and entrepreneurial ability through knowledge management perspective among undergraduate students base on SEM-PLS," in Proceedings of the Global Conference on Business and Economics Research (GCBER) 2017, Universiti Putra Malaysia, Malaysia, August 2017.

[6] H. Jiang, W. Xiong, and Y. Cao, "Research on the mechanism of entrepreneurial education quality, entrepreneurial self-efficacy and entrepreneurial intention in social sciences, engineering and science education," Eurasia Journal of Mathematics, Science and Technology Education, vol. 13, no. 7, pp. 3709-3721, 2017.

[7] J. Haltiwanger, E. Hurst, J. Miranda, and A. Schoar, "Introduction to measuring entrepreneurial businesses: current knowledge and challenges," in Measuring Entrepreneurial Businesses: Current Knowledge and ChallengesUniversity of Chicago Press, Chicago, Illinois, United States, 2016.

[8] M. C. Bayon and Y. Vaillant, "International variations in the impact of perceived entrepreneurial ability and actual ability on entrepreneurial activities," Strategic Change, vol. 25, no. 2, pp. 131-150, 2016.
[9] B. Hynes, N. Kennedy, and J. Pettigrew, "The role of business schools in framing entrepreneurial thinking across disciplines: the case of allied health professions," in Proceedings of the Innovative Business Education Design for 21st Century Learning, pp. 75-91, Springer International Publishing, Switzerland, June 2016.

[10] A. M. B. Alizadeh, M. Abbaszadeh, and S. Hayati, The Relationship between Social Intelligence with Entrepreneurial Ability Graduate Students of Tabriz University, 2016.

[11] J. Liu, "Research on the competency model of innovative entrepreneurial team based on network information data mining technology," RISTI (Revista Iberica de Sistemas e Tecnologias de Informacao), vol. E5, pp. 260-273, 2016.

[12] G. Anggadwita, B. S. Luturlean, V. Ramadani, and V. Ratten, "Socio-cultural environments and emerging economy entrepreneurship," Journal of Entrepreneurship in Emerging Economies, vol. 9, no. 1, pp. 85-96, 2017.

[13] M. Cook, "Essays on occupational choice and entrepreneurial ventures," Publicly Accessible Penn Dissertations, 2016, https:// repository.upenn.edu/edissertations/1668.

[14] I. Kusumaningrum and H. Hidayat, "Learning outcomes in vocational education: a business plan development by production-based learning model approach," International Journal of Environmental \& Science Education, vol. 11, no. 18, pp. 11917-11930, 2016.

[15] D. K. Panda, "Entrepreneurial orientation, intermediation services, microfinance, and microenterprises," Managerial and Decision Economics, vol. 39, 2017. 